\title{
BMJ Open Impact of point-of-care $C$ reactive protein in ambulatory care: a systematic review and meta-analysis
}

\author{
Jan Y Verbakel, ${ }^{1,2,3}$ Joseph J Lee, ${ }^{1,3}$ Clare Goyder, ${ }^{1,3}$ Pui San Tan, ${ }^{3}$ \\ Thanusha Ananthakumar, ${ }^{1,3}$ Philip J Turner, ${ }^{1,3}$ Gail Hayward, ${ }^{1,3}$ Ann Van den Bruel ${ }^{1,2}$
}

To cite: Verbakel JY, Lee JJ, Goyder C, et al. Impact of point-of-care $\mathrm{C}$ reactive protein in ambulatory care: a systematic review and meta-analysis. BMJ Open 2019;9:e025036. doi:10.1136/ bmjopen-2018-025036

- Prepublication history and additional material for this paper are available online. To view these files, please visit the journal online (http://dx.doi. org/10.1136/bmjopen-2018025036).

Received 26 June 2018 Revised 2 November 2018 Accepted 12 December 2018

Check for updates

(C) Author(s) (or their employer(s)) 2019. Re-use permitted under CC BY-NC. No commercial re-use. See rights and permissions. Published by BMJ.

${ }^{1}$ Nuffield Department of Primary Care Health Sciences, NIHR Community Healthcare MIC, University of Oxford, Oxford, UK ${ }^{2}$ Department of Public Health and Primary Care, KU Leuven (University of Leuven), Leuven, Belgium

${ }^{3}$ Nuffield Department of Primary Care Health Sciences, University of Oxford, Oxford, Oxfordshire, UK

Correspondence to

Professor Jan Y Verbakel;

jan.verbakel@phc.ox.ac.uk

\section{ABSTRACT}

Objective The aim of this review was to collate all available evidence on the impact of point-of-care $C$ reactive protein (CRP) testing on patient-relevant outcomes in children and adults in ambulatory care.

Design This was a systematic review to identify controlled studies assessing the impact of point-ofcare CRP in patients presenting to ambulatory care services. Ovid Medline, Embase, Cochrane Database of Systematic Reviews, Cochrane CENTRAL, DARE, Science Citation Index were searched from inception to March 2017.

Eligibility criteria for selecting studies Controlled studies assessing the impact of point-of-care CRP in patients presenting to ambulatory care services, measuring a change in clinical care, including but not limited to antibiotic prescribing rate, reconsultation, clinical recovery, patient satisfaction, referral and additional tests. No language restrictions were applied.

Data extraction Data were extracted on setting, date of study, a description of the intervention and control group, patient characteristics and results. Methodological quality of selected studies and assessment of potential bias was assessed independently by two authors using the Cochrane Risk of Bias tool.

Results 11 randomised controlled trials and 8 nonrandomised controlled studies met the inclusion criteria, reporting on 16064 patients. All included studies had a high risk of performance and selection bias. Compared with usual care, point-of-care CRP reduces immediate antibiotic prescribing (pooled risk ratio $0.81 ; 95 \% \mathrm{Cl} 0.71$ to 0.92$)$, however, at considerable heterogeneity $\left(I^{2}=72 \%\right)$. This effect increased when guidance on antibiotic prescribing relative to the CRP level was provided (risk ratios of $0.68 ; 95 \% \mathrm{Cl} 0.63$ to 0.74 in adults and 0.56 ; $95 \% \mathrm{Cl} 0.33$ to 0.95 in children). We found no significant effect of point-of-care CRP testing on patient satisfaction, clinical recovery, reconsultation, further testing and hospital admission.

Conclusions Performing a point-of-care CRP test in ambulatory care accompanied by clinical guidance on interpretation reduces the immediate antibiotic prescribing in both adults and children. As yet, available evidence does not suggest an effect on other patient outcomes or healthcare processes.

PROSPERO registration number CRD42016035426; Results.

\section{Strengths and limitations of this study}

- A systematic review and meta-analysis to assess the impact of point-of-care $C$ reactive protein on patient-relevant outcomes in ambulatory care.

- Our comprehensive approach resulted in a heterogeneous group of outcomes, patient populations and study designs.

- A paucity of data for children resulted in wide Cls around effect estimates.

- A lack of blinding of the clinicians and patients is inherent to trials examining the clinical impact of an intervention.

\section{INTRODUCTION}

$\mathrm{C}$ reactive protein (CRP) is an acute-phase protein, produced in the liver, which rises in response to tissue damage or inflammation, for example, from infection, but also in other inflammatory processes such as an acute exacerbation of Crohn's disease. ${ }^{1}$ Until recently, CRP blood tests have played only a minor role in ambulatory care because the delay between testing and result meant results were available too late to influence management decisions. ${ }^{2}$ Point-of-care (POC) tests are being gradually introduced in different healthcare settings and their use is expected to increase dramatically, ${ }^{34}$ with POC CRP tests now available providing a result within 4 min. ${ }^{56}$ Ambulatory care deals with a large amount of non-specific presentations, such as infectious diseases. Diagnostic tools for acute conditions are fairly limited and mostly reliant on clinical assessment. ${ }^{7-9}$ The more precise assessment would be welcome to mitigate increasing rates of patients referred to secondary care, and render diagnostic assessment in ambulatory care safer. ${ }^{10}$

In addition, diagnostic uncertainty can lead to inappropriate antibiotic prescribing, unnecessary referrals to hospital and unwarranted additional testing due to concern about potential serious infection. ${ }^{8}$ Primary 
care is where the majority of antibiotics are prescribed, most of which are for respiratory infections. Children are a particularly high-risk group for unnecessary antibiotic prescribing. ${ }^{11}$ As well as the global threat of widespread antimicrobial resistance, individuals with resistant infections in primary care are more likely to have the clinical failure to subsequent antibiotic treatment. ${ }^{12}$ Introducing better diagnostic tests might strengthen the assessment of infections in ambulatory care ${ }^{13}$ General practitioners (GPs) have indicated that they would like to use these POC tests to help them decide whether or not to start antibiotic treatment for patients with respiratory tract infections (RTIs) if rigorous evidence of the impact on patient pathways are available. ${ }^{14}$

In ambulatory care, CRP has been evaluated (mostly diagnostic accuracy studies with only very few trials) for the diagnosis of lower RTIs in adults, identify serious infections in children and reduce inappropriate antibiotic prescribing. ${ }^{9}{ }^{15}$ Since its introduction in routine care in Scandinavia in the early 1990s, prior to any solid evidence on the potential impact, ${ }^{16}$ POC CRP has been incorporated in the Dutch and UK guidelines to assist antibiotic prescribing decisions in adults with symptoms of lower RTIs. ${ }^{1718}$ Both recommendations are based on the same three randomised controlled trials (RCTs) (two randomised at the practice level and one at patient level), showing a significant reduction in immediate antibiotic prescribing rate when POC CRP was used (risk ratios (RRs) ranging from 0.54 to 0.77$).{ }^{19-21}$

A recent Cochrane review, involving six trials, confirmed that POC CRP can reduce antibiotic prescribing in adults with acute RTIs by $22 \%,{ }^{14}$ however, the broader impact on other clinically relevant outcomes, such as hospital admissions, missed diagnoses, inducing indication creep, ${ }^{22}$ reconsultation, further testing and patient satisfaction and in other patient groups, such as children, has yet to be confirmed. ${ }^{15}$

This systematic review forms part of a series of reviews to assess the impact of any POC tests in ambulatory care. Here, we aim to collate all available evidence on the impact of POC CRP testing in ambulatory care.

\section{METHODS}

Our objective was to assess the impact of POC CRP in patients presenting to ambulatory care services, resulting in a change in clinical care, including but not limited to antibiotic prescribing rate, reconsultation, clinical recovery, patient satisfaction, referral and additional tests.

\section{Search strategy}

We searched six electronic databases (MEDLINE, Cochrane Central Register of Controlled Trials, EMBASE, Cochrane CENTRAL, DARE, Science Citation Index). The first search was undertaken in November 2015 with an update undertaken in March 2017. No time or language restrictions were applied. We checked reference lists of all retrieved articles included in the final review.
The full search strategy is included in online supplementary file 1 .

\section{Selection of studies}

Studies were eligible if they reported the impact of POC testing on clinically relevant outcomes in ambulatory care settings. Ambulatory care was defined as any outpatient setting including primary care, walk-in clinics and emergency departments. Studies in hospitalised patients were excluded. In addition, we excluded conference abstracts, diagnostic accuracy studies (focussing only on the performance of a POC test vs a central lab test), qualitative studies, studies without a control group and systematic reviews although their references were checked for potential relevance. Title and abstract screening was done in pairs by six independent reviewers (CG, PST, JYV, TA and JJL). Discrepancies between the reviewers were resolved by a third independent reviewer of the team. For this paper, studies on POC CRP testing were identified from the overall selection by two independent researchers (JYV and CG).

\section{Data extraction and assessment of methodological quality}

Data were extracted by one reviewer (JYV) and checked by a second reviewer (JJL), and included setting, date of study, a description of the intervention and control group, patient characteristics and results.

Methodological quality of selected studies and assessment of potential bias was assessed independently by two authors (JYV and JJL). Any disagreements were resolved by a discussion involving a third member of the team. We used the Cochrane Risk of Bias tool for RCTs, ${ }^{23}$ extended for non-randomised but experimental and controlled studies by an assessment of a set of prespecified confounders, including whether baseline characteristics were reported, whether intervention and control groups were similar, and whether there was a detailed description of the usual care pathway. For case-control studies, we applied the Newcastle-Ottawa scale. ${ }^{24}$

\section{Outcome assessment}

The primary outcome of interest was the impact of POC on clinically relevant outcomes such as the antibiotic prescribing rate at the index consultation and during follow-up, reconsultation, referral or admission to hospital and mortality. Secondary outcomes included clinical recovery, patient satisfaction, RTIs during follow-up, referral for chest X-ray, additional tests performed, time to symptom resolution and adherence to antibiotic treatment.

\section{Patient involvement}

This paper is part of the National Institute for Health Research (NIHR) Diagnostic Evidence Cooperative (DEC) Oxford portfolio, and as such benefits from reflection and advice from the DEC's standing patient and public involvement (PPI) panel. Our panel has shown great interest in the introduction of POC tests in ambulatory care, especially in relation to the assessment of acutely 
ill children and the monitoring of anticoagulant therapy. The credibility of the test result, funding of testing strips and how to deal with intermediate results have been raised by our PPI panel in relation to POC testing.

\section{Data analysis and synthesis}

Meta-analyses were conducted separately for RCTs and non-randomised studies. For cluster RCTs, we adjusted the unit of analysis by calculating the design effect to modify sample sizes (with the formula ' $1+(\mathrm{M}-1)$ *ICC' with $\mathrm{M}$ representing the number of clusters and ICC the intracluster correlation coefficient, both extracted from the original publication) and inflate CIs accordingly. ${ }^{25}$ Individual study estimates were pooled in a meta-analysis using Mantel-Haenszel random-effects models for RR estimates and inverse-variance random-effects models were used for mean difference estimates. Study-to-study heterogeneity was assessed using the $\mathrm{I}^{2}$ test statistic in combination with visual inspection of the forest plots. For RTI during follow-up, antibiotics prescribed for RTI during follow-up, time to symptom resolution, adherence to antibiotic treatment and antibiotic prescribing rate (if absolute numbers were unavailable), we used mean differences and their corresponding 95\% CIs. Whenever data on mean differences were missing, we followed recommendations in the Cochrane Handbook for Systematic Reviews of Interventions to approximate the mean and $\mathrm{SD}$ from the reported $\mathrm{IQR}^{23}$

Subgroup analyses were limited to the type of randomisation (at cluster (practice) or patient level), age group (children vs adults) and whether or not CRP cut-off guidance was applied. We performed meta-regression using the metareg function (meta package in $\mathrm{R}$ ) to assess whether heterogeneity could be explained by age or the provision of CRP cut-off guidance. We created funnel plots to explore publication bias and small study effects when at least 10 studies were available for a particular outcome. Citation processing was done with Covidence (https://www.covidence.org/). Meta-analysis was undertaken with RevMan V.5.3, meta-regression with R V.3.4.3.

\section{RESULTS}

\section{Description of studies}

Databases were searched and yielded 26124 records. After full-text assessment in the overall review on POC testing in ambulatory care, 225 records were included, of which 19 studies were on POC CRP testing. These included studies comprising 11 RCTs and 8 non-randomised studies reporting on 16064 patients in total (table 1). Details of the search strategy and screening are provided in (online supplementary files 1 and 2).

Sixteen studies on POC CRP testing were excluded at full-text screening because they were not in an ambulatory care setting, ${ }^{26}{ }^{27}$ no comparator group without POC CRP testing was present, ${ }^{28-31}$ the effect of the POC CRP could not be assessed separately or did not guide treatment decisions, ${ }^{32-34}$ the focus was cost-effectiveness modelling ${ }^{35-37}$ or decision-making analysis, ${ }^{38} 39$ or it was not a clinical trial (study protocol or response to systematic review) ${ }^{40}{ }^{41}$ (online supplementary file 3 ).

\section{Included studies}

Twelve studies included adult patients only (totalling 7778 patients), ${ }^{19-21}{ }^{42-50}$ three studies included children only (3598 patients) $)^{95152}$ and four studies both (4688 patients) ${ }^{53-56}$ Of the 11 randomised trials, five were randomised at practice level (cluster randomised) $)^{192424357}$ and six at a patient level only (individually randomised). ${ }^{20} 44$ 51-54 Most studies included patients with RTIs (16 out of 19 in total), of which eight studies concerned lower respiratory tract only. ${ }^{19} 2042-454956$ Two studies included patients with sinusitis, tonsillitis or otitis media, ${ }^{455}$ whereas three studies included patients presenting with any acute illness. ${ }^{50} 5257$

Ten studies tested CRP on the NycoCard Reader II (by Alere), ${ }^{19} 20434448-50535456$ four studies on the Afinion AS100 Analyzer (Alere), ${ }^{42} 465257$ three on the QuikRead, ${ }^{21} 4750$ and one study tested CRP on the QuikRead Go (both by Orion Diagnostica). ${ }^{51}$ Antibiotic prescribing rate was reported as the primary outcome in 17 of the 19 studies, ${ }^{19-21} 42$ 44-47 49-57 reconsultation within 28 days in six studies, ${ }^{19-21} 424754$ clinical recovery within 7 and/or 28 days in five studies, ${ }^{19} 20424453$ and referral ${ }^{9} 5152$ or admission to hospital, ${ }^{9154}$ both in three studies (online supplementary file 3). Only one study reported on mortality, but none of the patients died during follow-up. ${ }^{9}$

Secondary outcomes were reported for patient satisfaction, ${ }^{19} 204754$ RTI during follow-up, ${ }^{43}$ referral for chest $\mathrm{X}$-ray, ${ }^{42}$ additional tests performed, ${ }^{52}$ time to symptom resolution ${ }^{54}$ and adherence to antibiotic treatment. ${ }^{48}$

\section{Risk of bias for included studies}

For the RCTs, overall methodological quality was high, with only two studies with an unclear or high risk of detection bias (lack of blinding of the outcome assessors), 5153 and two studies with an unclear risk of reporting bias (no study protocol available).44 53 Considering only studies that focused on the impact of POC tests were included, blinding of doctors to testing status was inherently impossible in these studies, resulting in a high risk of performance bias in all studies (online supplementary file 4). The non-randomised and before-after studies suffered from a high risk of selection, performance and detection bias, with an unclear risk of reporting bias, as there was no protocol available. ${ }^{45-5055}$ For the single case-control study, the comparability of cases and controls was scored as 'high risk', due to significant differences in sex, age and severity of intellectual disability, as well as an unclear risk due to non-reporting of the non-response rate. ${ }^{56}$

\section{Antibiotic prescribing rate}

Immediate prescribing at the index consultation

Based on 10 RCTs, performing a POC CRP test resulted in a reduction of antibiotic prescriptions issued at the index consultation with a pooled effect estimate RR of $0.81(95 \%$ 


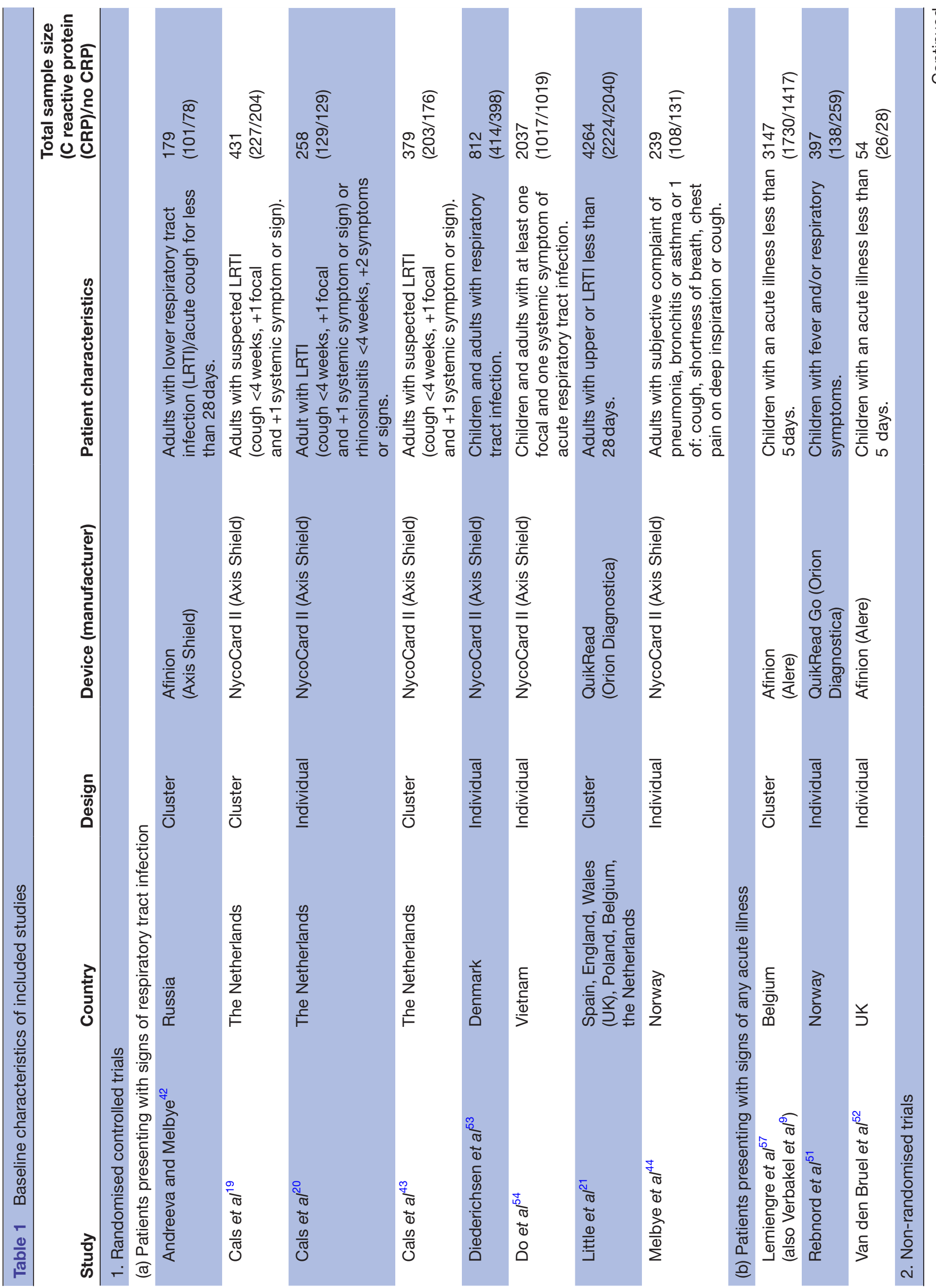




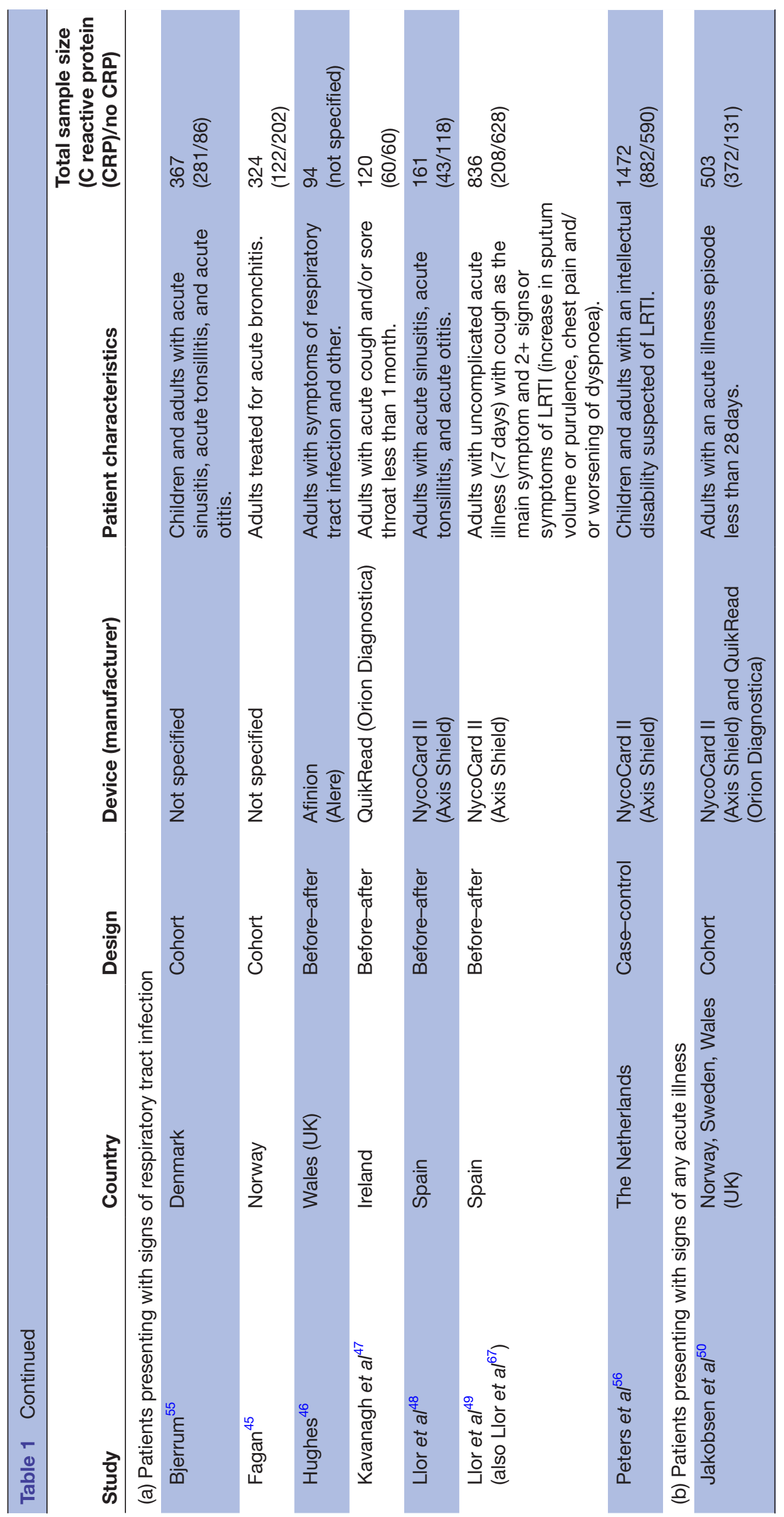

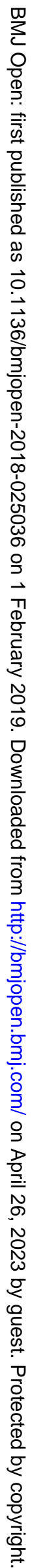


A

Point-of-care CRP usual care

Risk Ratio

Study or Subgroup Events
cluster randomised trials

Total Events Total Weight M-H, Random, 95\% Cl

Risk Ratio

Andreeva 2014

Cals 2009

$\begin{array}{lllll}18 & 49 & 22 & 38 & 5.5 \%\end{array}$

Lemiengre 2014

$\begin{array}{llll}65 & 31 & 59 & 5.8 \%\end{array}$

Little 2013

$\begin{array}{lllll}117 & 455 & 106 & 381 & 11.5 \%\end{array}$

Subtotal $(95 \% \mathrm{Cl})$

$\begin{array}{llrr}920 & 407 \quad 844 & 15.5 \%\end{array}$

1489

$1322 \quad 38.2 \%$

$\begin{array}{lcc}\text { Total events } & 459 & 566 \\ \text { Heterogeneity: } \mathrm{Tau}^{2}=0.02 ; \mathrm{Chi}^{2}=6.62, \mathrm{df}=3(\mathrm{P}=0.08) ; \mathrm{I}^{2}=55 \%\end{array}$

Test for overall effect: $Z=3.21(P=0.001)$

\begin{tabular}{lrrrrr}
\multicolumn{2}{c}{ individually randomised trials } \\
Cals 2010 & 56 & 129 & 73 & 129 & $10.6 \%$ \\
Diederichsen 2008 & 179 & 414 & 184 & 398 & $14.1 \%$ \\
Do 2016 & 441 & 1017 & 647 & 1019 & $16.4 \%$ \\
Melbye 1995 & 54 & 108 & 68 & 131 & $10.6 \%$ \\
Rebnord 2017 & 36 & 138 & 57 & 259 & $7.3 \%$ \\
Van den Bruel 2016 & 10 & 26 & 9 & 28 & $2.7 \%$ \\
Subtotal (95\% Cl) & & 1832 & & 1964 & $\mathbf{6 1 . 8 \%}$ \\
Total events & 776 & & 1038 & &
\end{tabular}

Heterogeneity: $\mathrm{Tau}^{2}=0.04 ; \mathrm{Chi}^{2}=24.04, \mathrm{df}=5(\mathrm{P}=0.0002) ; \mathrm{I}^{2}=79 \%$

Test for overall effect: $Z=1.28(P=0.20)$

Total $(95 \% \mathrm{Cl})$

3321

Total events $1235 \quad 1604$

Heterogeneity: $\mathrm{Tau}^{2}=0.02 ; \mathrm{Chi}^{2}=31.82, \mathrm{df}=9(\mathrm{P}=0.0002) ; \mathrm{I}^{2}=72 \%$

Test for overall effect: $Z=3.21(P=0.001)$

Test for subgroup differences: $\mathrm{Chi}^{2}=1.90, \mathrm{df}=1(\mathrm{P}=0.17), \mathrm{I}^{2}=47.5 \%$

$0.63[0.40,1.00]$

$0.59[0.38,0.91]$

$0.92[0.74,1.16]$

$0.69[0.61,0.77]$

$0.73[0.60,0.88]$

$0.77[0.60,0.98]$

$0.94[0.80,1.09]$

$0.68[0.63,0.74]$

$0.96[0.75,1.24]$

$1.19[0.82,1.70]$

$1.20[0.58,2.47]$

$0.88[0.73,1.07]$

$0.81[0.71,0.92]$

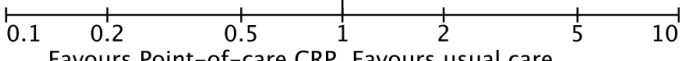

$\mathrm{M}-\mathrm{H}$, Random, 95\% Cl

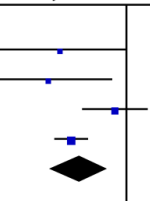

B

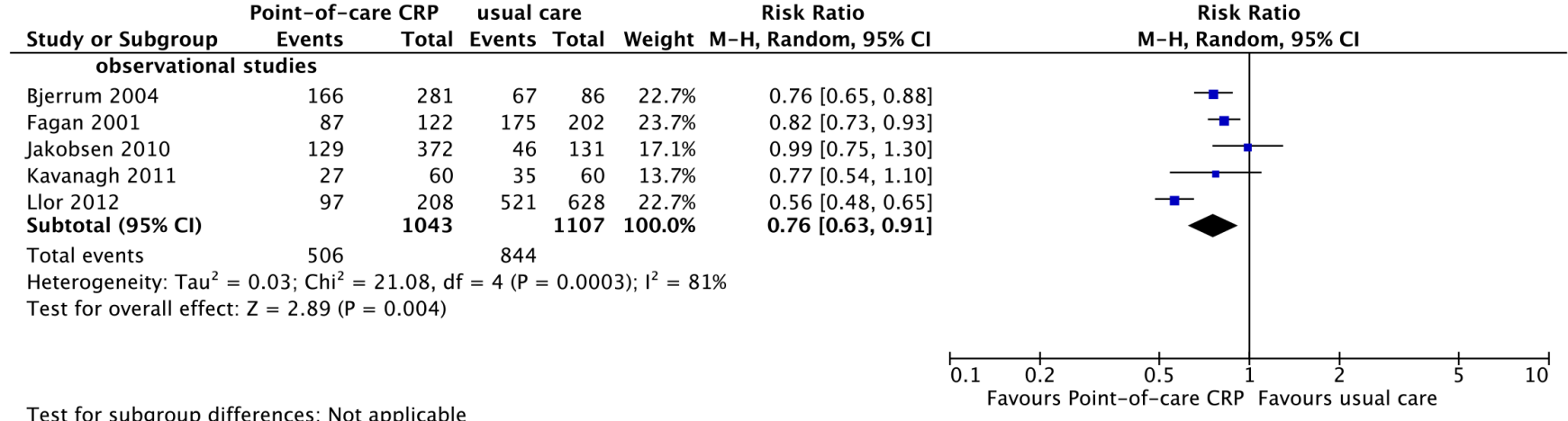

Figure 1 Forest plot of comparison: point-of-care CRP versus usual care, outcome: antibiotic prescribing at index consultation: (A) all patients, RCTs; (B) all patients, non-randomised studies. CRP, C reactive protein; M-H, Mantel-Haenszel; $\mathrm{RCTs}$, randomised controlled trials.

CI 0.71 to 0.92$)$, but heterogeneity was high $\left(\mathrm{I}^{2}=72 \%\right)$ (figure 1A). ${ }^{19-21} 424451-5457$ The five non-randomised studies (all on adult populations) suggested an even larger reduction with an RR 0.76 (95\% CI 0.63 to 0.91 ), again with high heterogeneity $\left(\mathrm{I}^{2}=81 \%\right)^{4547495055}$ (figure 1B).

Subgroup analyses by age (adult vs children $<18$ years) showed that the largest reductions were seen in adult populations (RR $0.75 ; 95 \%$ CI 0.66 to $0.86, \mathrm{I}^{2}=63 \%$ ). ${ }^{19-21} 42445354$ Five RCTs examining antibiotic prescribing in children found a pooled RR 0.93 (95\% CI 0.72 to $1.21, \mathrm{I}^{2}=74 \%$ ) (online supplementary file 5).

Five studies (all in adults) providing guidance on when to initiate antibiotic treatment by CRP level showed an overall RR 0.68 (95\% CI 0.63 to 0.74 , $\left.\mathrm{I}^{2}=0 \%\right),{ }^{19-214254}$ whereas two RCTs where no guidance was applied found no effect (RR $0.93 ; 95 \%$ CI 0.81 to 1.06 , $\mathrm{I}^{2}=0 \%$ ) (figure $\left.2 \mathrm{~A}\right) .{ }^{4453}$
A similar effect was seen in children, where two studies providing guidance resulted in fewer antibiotic prescriptions (RR $0.56 ; 95 \%$ CI 0.33 to 0.95$),{ }^{54} 57 \mathrm{I}^{2}=79 \%$ ), (figure 2B) whereas no effect was found in the four remaining studies providing no guidance (RR 1.01; $95 \%$ CI 0.85 to $\left.1.20, \mathrm{I}^{2}=0 \%\right) .{ }^{51-5357}$

In addition to the 10 RCTs mentioned above, we also identified one before-after study, which reported a significant decrease of antibiotic prescribing (mean percentage difference $-21.4 \%$; $95 \%$ CI -28.0 to $-14.8 \%)$. $^{46}$

Using meta-regression, heterogeneity could be explained by both the age group (adults vs children, $100 \%$ of between-study heterogeneity explained) and prescribing guidance $(100 \%$ and $85.9 \%$ of between-study heterogeneity accounted for, in adults and children, respectively, with residual between-study heterogeneity of $6.9 \%$ in children) (online supplementary file 6 ). 
A

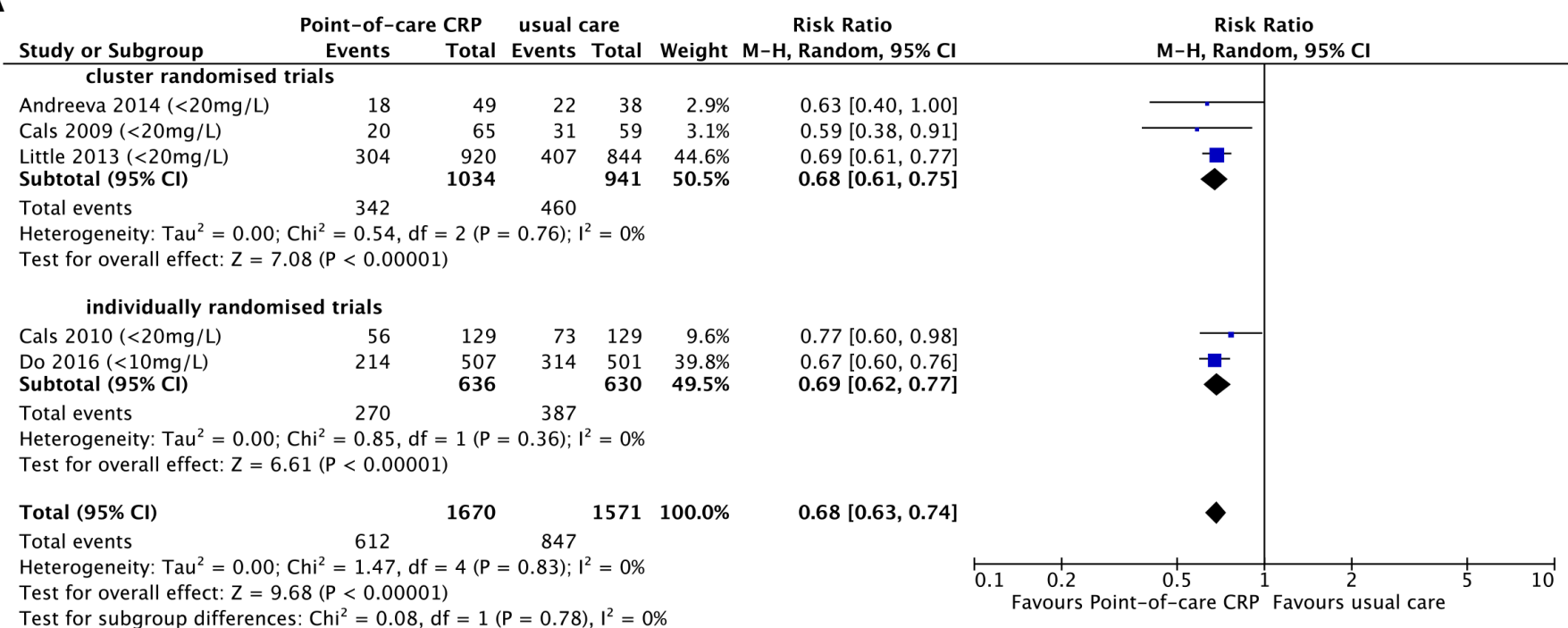

B

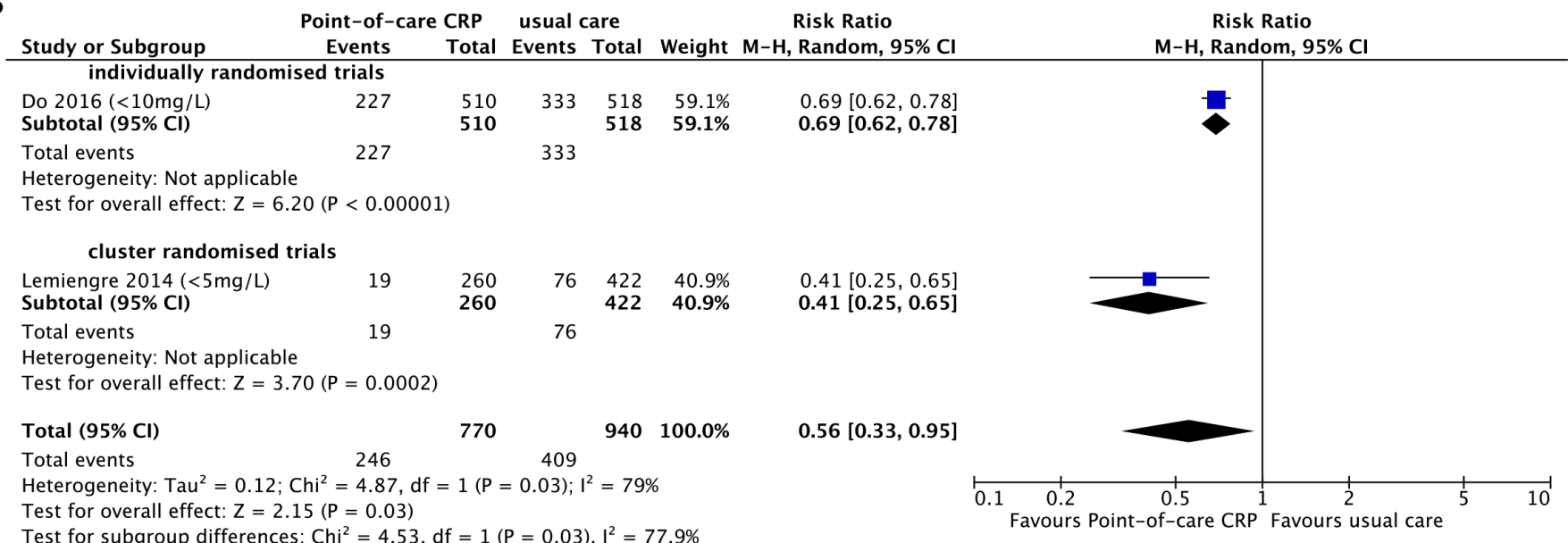

Figure 2 Forest plot of comparison: point-of-care CRP versus usual care, outcome: antibiotic prescribing at index consultation: (A) RCTs, adults only, if cut-off guidance applied; (B) RCTs, children only, if cut-off guidance applied. CRP cut-off used to withhold antibiotic treatment between brackets. CRP, $\mathrm{C}$ reactive protein; $\mathrm{M}-\mathrm{H}$, Mantel-Haenszel; RCTs, randomised controlled trials.

\section{Prescribing during follow-up}

Antibiotic prescriptions within 28 days of testing were slightly lower with a POC CRP test (RR $0.84 ; 95 \%$ CI 0.72 to 0.99$)$ at moderate heterogeneity $\left(\mathrm{I}^{2}=46 \%\right)$ for the five available RCTs. ${ }^{1920424454}$ One RCT, however, did not find a significant reduction in antibiotic treatments for RTIs during long-term follow-up with a mean difference of $-5 \%(95 \% \text { CI }-13 \% \text { to }+3 \%)^{43}$ (online supplementary file $7)$.

The single case-control study found a larger effect with an RR 0.46 (95\% CI 0.37 to 0.57$).{ }^{56}$

\section{Referral and admission to hospital}

We found no difference in the number of patients referred to a hospital (overall RR 0.84 (95\% CI 0.44 to 1.61 ) with low heterogeneity $\left(I^{2}=18 \%\right)^{95152}$ (online supplementary file 8). Three RCTs reporting the number of patients admitted to hospital showed a non-significant increase when POC CRP was used with an RR 1.24 (95\% CI 0.64 to $\left.2.43, \mathrm{I}^{2}=18 \%\right) .{ }^{9}{ }^{2154}$

\section{Reconsultation}

Reconsultations were not different for patients receiving POC CRP compared with usual care, in the five RCTs (RR 1.09 (95\% CI 0.93 to $1.27, \mathrm{I}^{2}=0 \%$ in each subgroup, $\mathrm{I}^{2}$ for subgroup differences (individually randomised RCTs vs cluster RCTs was 45\%) ) ${ }^{19-214254}$ and the before-after study (RR 1.56 (95\% CI 0.73 to 3.32 ) $)^{47}$ (online supplementary file 9$)$.

\section{Secondary outcomes}

Clinical recovery within 7 and 28 days, patient satisfaction, number of additional tests performed and time to symptom resolution did not differ between patients 
Table 2 Secondary outcomes: results

\begin{tabular}{|c|c|c|c|c|}
\hline Secondary outcome & Studies & $\begin{array}{l}\text { (Pooled) risk ratio or mean } \\
\text { difference }(\%) \text { of } \\
\text { POC CRP versus usual care }\end{array}$ & $95 \% \mathrm{Cl}$ & $\begin{array}{l}\text { Heterogeneity } \\
I^{2}(\%)\end{array}$ \\
\hline Clinical recovery within 7 days & 204453 & 1.03 & 0.93 to 1.14 & 0 \\
\hline Clinical recovery within 28 days & 194244 & 0.94 & 0.69 to 1.28 & 0 \\
\hline \multirow[t]{2}{*}{ Patient satisfaction } & 192054 & 0.82 & 0.55 to 1.21 & 48 \\
\hline & 47 & 1.00 & 0.43 to 2.34 & NA \\
\hline No of additional tests & 952 & 1.17 & 0.79 to 1.72 & 0 \\
\hline No of chest X-rays & 42 & 0.72 & 0.53 to 0.98 & NA \\
\hline Time to symptom resolution & 54 & +0 days & -19 to +19 days & NA \\
\hline Adherence to antibiotic treatment & 48 & $+8.9 \%$ & $+3.4 \%$ to $+14.4 \%$ & NA \\
\hline
\end{tabular}

CRP, C reactive protein; GP, general practitioners; NA, not applicable; POC, point-of-care, RTI, respiratory tract infections.

tested with POC CRP and usual care (table 2). A single RCT found a slight reduction $(-16 \%)$ in number of RTIs (registered by the GP) during follow-up. ${ }^{43}$ Another RCT detected a reduction in the number of patients referred for chest X-ray in favour of POC CRP. ${ }^{42}$ A before-after study in patients with acute sinusitis, tonsillitis and otitis found a higher adherence to antibiotic treatment $(+9 \%$ of antibiotics containers opened) in patients tested with POC CRP $^{48}$ (online supplementary file 10).

\section{Publication bias}

For the three primary outcomes where funnel plots were possible (antibiotic prescribing at index consultation, antibiotic prescribing within 28 days and reconsultation within 28 days), there was no apparent evidence of publication bias, although only studies with small effect sizes were identified in this review. (online supplementary file 11).

\section{DISCUSSION}

Performing a POC CRP test in ambulatory care accompanied by clinical guidance can reduce the immediate antibiotic prescribing rate in both adults and children presenting to their GP with an acute infection. POC in the absence of clinical guidance was effective at reducing antibiotic prescriptions in adults but not in children. We did not find a significant effect of POC CRP on clinical recovery, reconsultation and subsequent management decisions, such as referral or delayed admission to hospital, although very few studies reported on the latter, resulting in residual uncertainty concerning the safety of POC CRP.

This review focused on the clinical impact of POC CRP on patient-relevant outcomes in ambulatory care, emphasising the importance of moving above and beyond the diagnostic accuracy of POC tests and examining their effect on clinical decision-making. ${ }^{58}$ Our comprehensive approach resulted in a heterogeneous group of outcomes, patient populations and study designs. However, our results were consistent across the different types of studies, suggesting these findings are robust and reflect clinical reality. Our subgroup analyses and meta-regressions have shown that much of the statistical heterogeneity could be explained by patient age and prescribing guidelines. When implementing POC CRP, these factors should be taken into account, guidance should be considered, especially in children. The paucity of data for children resulted in wide CIs around our effect estimates, emphasising the need for large trials in children in ambulatory care. ${ }^{2}$ Our search was updated in March 2017, potentially overlooking relevant papers published in the past 12 months.

The issue of performance bias due to a lack of blinding of the clinicians and patients is inherent to trials examining the clinical impact of an intervention and therefore will not be improved in future studies. ${ }^{59}$

Before POC tests are widely adopted, GPs want evidence of their accuracy, rigorous testing of the impact on patient-relevant outcomes and consideration of test funding. ${ }^{14}$

Previous studies have focused on the diagnostic accuracy of POC CRP in ambulatory care,${ }^{960}$ including a recent individual patient data meta-analysis that concluded that adding CRP measurements to the diagnostic workup in ambulatory care improved risk classification of patients suspected of pneumonia. ${ }^{60}$ Systematic reviews have mainly prioritised antibiotic prescribing rate in RTIs and found a significant reduction when POC CRP was used, similar to our findings. ${ }^{1561}$ The current National Institute for Health and Care Excellence pneumonia guideline advises GPs to consider a delayed prescription in patients with intermediate CRP values. ${ }^{17}$ A recent umbrella review found that CRP is one of three effective strategies to reduce antibiotic prescribing, alongside shared decision-making and procalcitonin-guided management. ${ }^{62}$ The current systematic review included a wider range of patient-relevant outcomes, demonstrated the impact of clinical guidance in addition to POC CRP on prescribing 
and demonstrated the relative lack of evidence in paediatric populations. A recent non-randomised study showed that having POC CRP results available influences the decision of GPs to prescribe antibiotic treatment in patients with an acute cough, but not in GPs with a low antibiotic prescribing rate. ${ }^{39}$ POC CRP testing has shown to be cost-effective in several studies, though this was not the focus of our review. ${ }^{3034-37}$

In order to justify adoption, POC tests need to demonstrate an overall benefit to patients and healthcare providers, regulators and commissioners must also be satisfied. It is vital to have robust evidence to ensure the consequences for patients and healthcare systems are properly evaluated. Broad adoption would be appropriate if a test can be applied in a wide range of patients and conditions. Our findings show POC CRP for use in ambulatory care meets these criteria as long as appropriate guidance is provided. GPs have indicated they require guidance on the use and interpretation of POC CRP cut-offs. ${ }^{6364}$ Further testing assessing broader impact and cost-effectiveness in children is needed.

Furthermore, other interventions, such as educating GPs, facilitating patient-centred care and decreasing diagnostic uncertainty often resulting in complex interventions, can be as effective in reducing antibiotic prescribing. ${ }^{2165}$ Communication training has been shown to have an effect on antibiotic prescribing. ${ }^{19}$ If implemented together with POC CRP, they even reinforced one another. However, a recent paper showed that communication intervention in children had the opposite effect, increasing the antibiotic prescribing rate. ${ }^{66}$ Arguably, communication training, if applied in the wrong population (eg, with an interest in decreasing prescribing behaviour), may have adverse effects. Similarly, when antibiotic prescribing rates are low from the outset, POC CRP may not be able to decrease rates further without becoming unsafe. Other safety issues associated with the use of POC CRP might still arise, especially in children. We found that mortality was generally under-reported and the impact on hospital admission rates has yet to be confirmed. Future studies should focus on the potential harms and assess the safety of implementing POC CRP in ambulatory care.

\section{CONCLUSIONS}

Performing a POC CRP test in ambulatory care accompanied by evidence-based clinical guidance on interpretation reduces the immediate antibiotic prescribing rate in both adults and children. As yet the evidence of impact on other patient outcomes or healthcare usage is lacking.

Acknowledgements This article presents independent research part funded by the NIHR former Diagnostic Evidence Co-operative (DEC) Oxford and ongoing Community Healthcare MIC. JYJV had full access to all the data in the study and takes responsibility for the integrity of the data and the accuracy of the data analysis.

Contributors JYV and JJL did data extraction. JYV performed the analyses, which were discussed with JJL, CG, PST, TA, PJT, GH, AvdB. JYV drafted this report and
JJL, CG, PST, TA, PJT, GH and AvdB codrafted and commented on the final version. All authors had full access to all of the data (including statistical reports and tables) in the study and take responsibility for the integrity of the data and the accuracy of the data analysis. JYV affirms that the manuscript is an honest, accurate and transparent account of the study being reported; that no important aspects of the study have been omitted. All authors have read and approved the final manuscript.

Funding This work was supported by the National Institute for Health Research (NIHR) School for Primary Care Research (Funding round 11, award number 309). CG is a Wellcome Trust Doctoral Fellow. JYV, TA, GH, PJT and AvdB were funded by the NIHR Community Healthcare MedTech and IVD Co-operative.

Disclaimer The views expressed are those of the authors and not necessarily those of the NHS, the NIHR or the Department of Health.

Competing interests None declared.

Patient consent for publication Not required.

Provenance and peer review Not commissioned; externally peer reviewed.

Data sharing statement All data for these analyses are included in the manuscript or online appendices. No additional data are available.

Open access This is an open access article distributed in accordance with the Creative Commons Attribution Non Commercial (CC BY-NC 4.0) license, which permits others to distribute, remix, adapt, build upon this work non-commercially, and license their derivative works on different terms, provided the original work is properly cited, appropriate credit is given, any changes made indicated, and the use is non-commercial. See: http://creativecommons.org/licenses/by-nc/4.0/.

\section{REFERENCES}

1. Pepys MB, Hirschfield GM. C-reactive protein: a critical update. J Clin Invest 2003;111:1805-12.

2. Van den Bruel A, Thompson M. Research into practice: acutely ill children. Br J Gen Pract 2014;64:311-3.

3. Abel G. Current status and future prospects of point-of-care testing around the globe. Expert Rev Mol Diagn 2015;15:853-5.

4. Sohn AJ, Hickner JM, Alem F. Use of Point-of-Care Tests (POCTs) by US Primary Care Physicians. J Am Board Fam Med 2016;29:371-6.

5. Minnaard MC, van de Pol AC, Broekhuizen BD, et al. Analytical performance, agreement and user-friendliness of five C-reactive protein point-of-care tests. Scand J Clin Lab Invest 2013;73:627-34.

6. Verbakel JY, Aertgeerts B, Lemiengre M, et al. Analytical accuracy and user-friendliness of the Afinion point-of-care CRP test. $J$ Clin Pathol 2014;67:83-6.

7. Buntinx F, Mant D, Van den Bruel A, et al. Dealing with low-incidence serious diseases in general practice. Br J Gen Pract 2011;61:43-6.

8. Van den Bruel A, Haj-Hassan T, Thompson M, et al. Diagnostic value of clinical features at presentation to identify serious infection in children in developed countries: a systematic review. Lancet 2010;375:834-45.

9. Verbakel JY, Lemiengre MB, De Burghgraeve T, et al. Should all acutely ill children in primary care be tested with point-of-care CRP: a cluster randomised trial. BMC Med 2016;14:131.

10. Thompson MJ, Ninis N, Perera R, et al. Clinical recognition of meningococcal disease in children and adolescents. Lancet 2006;367:397-403.

11. Ashdown HF, Räisänen $U$, Wang $K$, et al. Prescribing antibiotics to 'at-risk' children with influenza-like illness in primary care: qualitative study. BMJ Open 2016;6:e011497.

12. van Hecke $\mathrm{O}$, Wang $\mathrm{K}$, Lee JJ, et al. Implications of Antibiotic Resistance for Patients' Recovery From Common Infections in the Community: A Systematic Review and Meta-analysis. Clin Infect Dis 2017;65:371-82.

13. Van den Bruel A, Thompson MJ, Haj-Hassan T, et al. Diagnostic value of laboratory tests in identifying serious infections in febrile children: systematic review. BMJ 2011;342:d3082.

14. Jones $\mathrm{CH}$, Howick J, Roberts NW, et al. Primary care clinicians' attitudes towards point-of-care blood testing: a systematic review of qualitative studies. BMC Fam Pract 2013;14:117.

15. Aabenhus R, Jensen JU, Jorgensen KJ, et al. Biomarkers as pointof-care tests to guide prescription of antibiotics in patients with acute respiratory infections in primary care. Cochrane Database Syst. Rev 2014;11:CD010130.

16. Hjortdahl P, Landaas S, Urdal P, et al. C-reactive protein: a new rapid assay for managing infectious disease in primary health care. Scand J Prim Health Care 1991;9:3-10. 
17. NICE. Pneumonia: Diagnosis and Management of Community- and Hospital-Acquired Pneumonia in Adults. London: National Institute for Health and Clinical Excellence, 2014.

18. Verheij T, Hopstaken RM, Prins JM, et al. NHG-Standaard Acuut hoesten. Huisarts \& Wetenschap 2011;54:86-92.

19. Cals JW, Butler CC, Hopstaken RM, et al. Effect of point of care testing for $\mathrm{C}$ reactive protein and training in communication skills on antibiotic use in lower respiratory tract infections: cluster randomised trial. BMJ 2009;338:b1374.

20. Cals JW, Schot MJ, de Jong SA, et al. Point-of-care C-reactive protein testing and antibiotic prescribing for respiratory tract infections: a randomized controlled trial. Ann Fam Med 2010;8:124-33

21. Little $P$, Stuart $B$, Francis $N$, et al. Effects of internet-based training on antibiotic prescribing rates for acute respiratory-tract infections: a multinational, cluster, randomised, factorial, controlled trial. Lancet 2013;382:1175-82.

22. Riggs KR, Ubel PA. The role of professional societies in limiting indication creep. J Gen Intern Med 2015;30:249-52.

23. Higgins JPT, Green S, Cochrane Collaboration. Cochrane handbook for systematic reviews of interventions. Chichester, England; Hoboken, NJ: Wiley-Blackwell, 2008.

24. Wells G, Shea B, O'Connell D, et al. The Newcastle-Ottawa Scale (NOS) for assessing the quality of nonrandomized studies in metaanalyses. 2013;3 http://www.ohri.ca/programs/clinical_epidemiology/ oxford.htm.

25. Higgins JPT, Green S. Cochrane Handbook for Systematic Reviews of Interventions Version 5.1.0 [Updated March 2011]. The Cochrane Collaboration. 2011 www.handbook.cochrane.org

26. Gonzales R, Aagaard EM, Camargo CA, et al. C-reactive protein testing does not decrease antibiotic use for acute cough illness when compared to a clinical algorithm. J Emerg Med 2011;41:1-7.

27. Nijman RG, Moll HA, Vergouwe Y, et al. C-Reactive Protein Bedside Testing in Febrile Children Lowers Length of Stay at the Emergency Department. Pediatr Emerg Care 2015;31:633-9.

28. Cohen $\mathrm{R}$, Lécuyer $\mathrm{A}$, Wollner $\mathrm{C}$, et al. [Evaluation of impact of CRP rapid test in management of febrile children in ambulatory pediatric practice]. Arch Pediatr 2008;15:1126-32.

29. Cohen R, Romain O, Levy C, et al. [Impact of CRP rapid test in management of febrile children in paediatric emergency units of llede-France]. Arch Pediatr 2006;13:1566-71.

30. Kokko E, Korppi M, Helminen M, et al. Rapid C-reactive protein and white cell tests decrease cost and shorten emergency visits. Pediatr Int 2014;56:698-701.

31. Muszynska A, Steciwko A, Buczek-Stachowska A, et al. Rational antibiotic therapy - rapid CRP tests value on the effect on antibiotic prescribing? - initial results. Fam Med Prim Care Rev 2007;9:541-4.

32. Elfving K, Shakely D, Andersson M, et al. Acute Uncomplicated Febrile Illness in Children Aged 2-59 months in Zanzibar Aetiologies, Antibiotic Treatment and Outcome. PLoS One 2016;11:e0146054.

33. Kankaanpää M, Raitakari M, Muukkonen L, et al. Use of point-ofcare testing and early assessment model reduces length of stay for ambulatory patients in an emergency department. Scand J Trauma Resusc Emerg Med 2016;24:125.

34. Dahler-Eriksen BS, Lauritzen T, Lassen JF, et al. Near-patient test for C-reactive protein in general practice: assessment of clinical, organizational, and economic outcomes. Clin Chem 1999;45:478-85.

35. Cals JW, Ament AJ, Hood K, et al. C-reactive protein point of care testing and physician communication skills training for lower respiratory tract infections in general practice: economic evaluation of a cluster randomized trial. J Eval Clin Pract 2011;17:1059-69.

36. Hunter R. Cost-effectiveness of point-of-care C-reactive protein tests for respiratory tract infection in primary care in England. Adv Ther 2015;32:69-85

37. Oppong R, Jit M, Smith RD, et al. Cost-effectiveness of point-of-care C-reactive protein testing to inform antibiotic prescribing decisions. Br J Gen Pract 2013;63:e465-e471.

38. Lindström J, Nordeman L, Hagström B. What a difference a CRP makes. A prospective observational study on how point-of-care C-reactive protein testing influences antibiotic prescription for respiratory tract infections in Swedish primary health care. Scand $J$ Prim Health Care 2015;33:275-82.

39. Minnaard MC, van de Pol AC, Hopstaken RM, et al. C-reactive protein point-of-care testing and associated antibiotic prescribing. Fam Pract 2016;33:408-13

40. Azevedo P, Costa J, Vaz-Carneiro A. [Analysis of the Cochrane review: biomarkers as point-of-care tests to guide prescription of antibiotics in patients with acute respiratory infections in primary care. Cochrane Database Syst Rev. 2014,11:CD10130]. Acta Med Port 2014:27:677-80.
41. Cals JW, Hopstaken RM, Butler CC, et al. Improving management of patients with acute cough by C-reactive protein point of care testing and communication training (IMPAC3T): study protocol of a cluster randomised controlled trial. BMC Fam Pract 2007;8:15.

42. Andreeva $\mathrm{E}$, Melbye $\mathrm{H}$. Usefulness of $\mathrm{C}$-reactive protein testing in acute cough/respiratory tract infection: an open cluster-randomized clinical trial with C-reactive protein testing in the intervention group. BMC Fam Pract 2014;15:80.

43. Cals JW, de Bock L, Beckers PJ, et al. Enhanced communication skills and C-reactive protein point-of-care testing for respiratory tract infection: 3.5-year follow-up of a cluster randomized trial. Ann Fam Med 2013;11:157-64.

44. Melbye H, Aaraas I, Fleten N, et al. [The value of C-reactive protein testing in suspected lower respiratory tract infections. A study from general practice on the effect of a rapid test on antibiotic research and course of the disease in adults]. Tidsskr Nor Laegeforen 1995;115:1610-5.

45. Fagan MS. [Can use of antibiotics in acute bronchitis be reduced?] Tidsskr Nor Laegeforen 2001;121:455-8.

46. Hughes A, Gwyn L, Sharman H CC. Evaluating a point-of-care C-reactive protein test to support antibiotic prescribing decisions in a general practice. the Pharmaceutical Journal 2016;18.

47. Kavanagh KE, O'Shea E, Halloran R, et al. A pilot study of the use of near-patient C-Reactive Protein testing in the treatment of adult respiratory tract infections in one Irish general practice. BMC Fam Pract 2011;12:93.

48. Llor C, Sierra N, Hernández S, et al. Impact of C-reactive protein testing on adherence to thrice-daily antibiotic regimens in patients with lower respiratory tract infection. Prim Care Respir J 2010;19:358-62.

49. Llor C, Bjerrum L, Arranz J, et al. C-reactive protein testing in patients with acute rhinosinusitis leads to a reduction in antibiotic use. Fam Pract 2012;29:653-8.

50. Jakobsen KA, Melbye H, Kelly MJ, et al. Influence of CRP testing and clinical findings on antibiotic prescribing in adults presenting with acute cough in primary care. Scand J Prim Health Care 2010;28:229-36.

51. Rebnord IK, Sandvik H, Mjelle AB, et al. Factors predicting antibiotic prescription and referral to hospital for children with respiratory symptoms: secondary analysis of a randomised controlled study at out-of-hours services in primary care. BMJ Open 2017;7:e012992.

52. Van den Bruel A, Jones C, Thompson M, et al. C-reactive protein point-of-care testing in acutely ill children: a mixed methods study in primary care. Arch Dis Child 2016;101:382-6.

53. Diederichsen HZ, Skamling M, Diederichsen A, et al. Randomised controlled trial of CRP rapid test as a guide to treatment of respiratory infections in general practice. Scand J Prim Health Care 2000;18:39-43.

54. Do NT, Ta NT, Tran NT, et al. Point-of-care C-reactive protein testing to reduce inappropriate use of antibiotics for non-severe acute respiratory infections in Vietnamese primary health care: a randomised controlled trial. Lancet Glob Health 2016;4:e633-41.

55. Bjerrum L, Gahrn-Hansen B, Munck AP. C-reactive protein measurement in general practice may lead to lower antibiotic prescribing for sinusitis. Br J Gen Pract 2004;54:659-62.

56. Peters CM, Schouwenaars FM, Haagsma E, et al. Antibiotic prescribing and C-reactive protein testing for pulmonary infections in patients with intellectual disabilities. $\mathrm{Br} J$ Gen Pract 2013;63:e326-e330.

57. Lemiengre MB, Verbakel JY, De Burghgraeve T, et al. Optimizing antibiotic prescribing for acutely ill children in primary care (ERNIE2 study protocol, part B): a cluster randomized, factorial controlled trial evaluating the effect of a point-of-care C-reactive protein test and a brief intervention combined with written safety net advice. BMC Pediatr 2014;14:246.

58. Verbakel JY, Turner PJ, Thompson MJ, et al. Common evidence gaps in point-of-care diagnostic test evaluation: a review of horizon scan reports. BMJ Open 2017;7:e015760.

59. Hróbjartsson A, Emanuelsson F, Skou Thomsen AS, et al. Bias due to lack of patient blinding in clinical trials. A systematic review of trials randomizing patients to blind and nonblind sub-studies. Int $J$ Epidemiol 2014:43:1272-83.

60. Minnaard MC, de Groot JAH, Hopstaken RM, et al. The added value of $\mathrm{C}$-reactive protein measurement in diagnosing pneumonia in primary care: a meta-analysis of individual patient data. CMAJ $2017 ; 189$

61. Huang Y, Chen R, Wu T, et al. Association between point-of-care CRP testing and antibiotic prescribing in respiratory tract infections: a systematic review and meta-analysis of primary care studies. $\mathrm{Br} J$ Gen Pract 2013;63:e787-e794. 
62. Tonkin-Crine SK, Tan PS, van Hecke O, et al. Clinician-targeted interventions to influence antibiotic prescribing behaviour for acute respiratory infections in primary care: an overview of systematic reviews. Cochrane Database Syst Rev 2017:9:CD012252.

63. Hardy V, Thompson M, Keppel GA, et al. Qualitative study of primary care clinicians' views on point-of-care testing for C-reactive protein for acute respiratory tract infections in family medicine. BMJ Open 2017;7:e012503.

64. Cals JW, Chappin FH, Hopstaken RM, et al. C-reactive protein pointof-care testing for lower respiratory tract infections: a qualitative evaluation of experiences by GPs. Fam Pract 2010;27:212-8.
65. Tonkin-Crine S, Yardley L, Little P. Antibiotic prescribing for acute respiratory tract infections in primary care: a systematic review and meta-ethnography. J Antimicrob Chemother 2011;66:2215-23.

66. Lemiengre MB, Verbakel JY, Colman R, et al. Reducing inappropriate antibiotic prescribing for children in primary care: a cluster randomised controlled trial of two interventions. Br J Gen Pract 2018;68:e204-e210.

67. Llor C, Bjerrum L, Munck A, et al. Access to point-of-care tests reduces the prescription of antibiotics among antibioticrequesting subjects with respiratory tract infections. Respir Care 2014;59:1918-23. 